\title{
Trafficking of immune cells in the central nervous system
}

\author{
Emma H. Wilson, ${ }^{1}$ Wolfgang Weninger, ${ }^{2}$ and Christopher A. Hunter ${ }^{3}$
}

\begin{abstract}
1Division of Biomedical Sciences, University of California, Riverside, California, USA. ${ }^{2}$ The Centenary Institute for Cancer Medicine and Cell Biology, Newtown, New South Wales, Australia. ${ }^{3}$ Department of Pathobiology, School of Veterinary Medicine, University of Pennsylvania,
\end{abstract}

Philadelphia, Pennsylvania, USA.

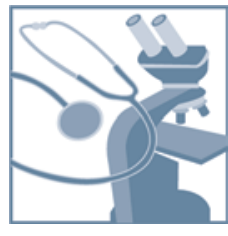

The CNS is an immune-privileged environment, yet the local control of multiple pathogens is dependent on the ability of immune cells to access and operate within this site. However, inflammation of the distinct anatomical sites (i.e., meninges, cerebrospinal fluid, and parenchyma) associated with the CNS can also be deleterious. Therefore, control of lymphocyte entry and migration within the brain is vital to regulate protective and pathological responses. In this review, several recent advances are highlighted that provide new insights into the processes that regulate leukocyte access to, and movement within, the brain.

The observations of Paul Ehrlich in the late 19th century that water-soluble vital dyes injected into the peripheral circulation would stain all organs except the brain provided the first indication that the CNS was anatomically separated from the rest of the body (1). Subsequent studies by Edwin Goldmann, showing that dye injected into the spinal fluid did not stain peripheral tissues, confirmed the idea that the brain was a unique anatomical compartment (2). We now know that this feature is a consequence of the existence of the blood-brain barrier (BBB), which limits access of soluble factors to the CNS and restricts access of immune cells to this site (3-5). Combined with the lack of an obvious lymphatic system, low constitutive levels of MHC class I and II molecules, local production of suppressive factors, and, in the normal state, limited numbers of professional antigen-presenting cells, these features all reinforced the concept of the CNS as an immune-privileged site $(6,7)$.

The work of Peter Medawar in 1948 on graft rejection provided some of the first experimental evidence indicating that the brain might not be an immunologically pristine site (8). Those experiments demonstrated that skin transplants in the brain of naive animals did not provoke an immune response, but if animals were first exposed to graft antigens, such that immune cells in the periphery were "educated" beforehand, grafts would be rejected. It is now appreciated that these events involve the ability of a graftspecific adaptive immune response that is primed in the periphery to access the CNS and mediate rejection of the foreign tissue (9). It is also apparent that cells of the immune system have access to the three distinct anatomical compartments (i.e., cerebrospinal fluid [CSF], meninges, and parenchyma of the brain) that are relevant to the CNS under physiological circumstances and disease states. Several neurodegenerative, physical, and infectious diseases can be modeled in the mouse, allowing direct analysis of inflammatory processes in the brain (Table 1) to corroborate observations from human postmortem tissue analysis, CSF samples, and biopsies. Thus, the presence in the brain of neutrophils in the context of bacterial meningitis (10), eosinophils associated with migrating

Conflict of interest: C.A. Hunter has received support for his research from Centocor Ortho Biotech Inc.

Citation for this article: J Clin Invest. 2010;120(5):1368-1379. doi:10.1172/JCI41911. helminths (11), T cells in post-vaccinal or post-infectious CNS autoimmunity (12), and plasma cells (Mott cells) during African sleeping sickness, which is caused by Trypanosoma spp. (13), illustrate that innate and adaptive immunity are operational at this site. Indeed, immune cells are required to control certain viral, bacterial, fungal, and parasitic pathogens that affect the brain. For example, infection with the parasite Toxoplasma gondii leads to a latent infection in the CNS, and T cells are essential for its longterm control. This is illustrated by the development of toxoplasmic encephalitis in previously infected individuals that acquire defects in $\mathrm{T}$ cell functions (14). This can be recapitulated in experimental models in which chronically infected mice depleted of T cells develop uncontrolled parasite replication in the brain $(15,16)$. A similar requirement for immune cells in the CNS has been shown for the control of many pathogens, including the human polyomavirus JC virus, which causes progressive multifocal leukoencephalopathy (17); Cryptococcus spp., which can cause meningitis; and cytomegalovirus (18), which can cause encephalitis. These examples illustrate the importance of immune surveillance in the CNS.

Although the ability to recognize infections in the CNS is required to limit pathogen replication, this response is not always beneficial. The presence of the rigid bone casing of the brain makes the classic features of an inflammatory response, such as swelling and expansion, a dangerous prospect. Similarly, the development of pathology associated with meningitis and/or encephalitis can lead to reduced neuronal function and survival $(19,20)$. In addition, although the immune system can contribute to the successful resolution of tissue damage associated with many CNS disorders $(21,22)$, there is also an appreciation that inflammation in the brain may contribute to the pathogenesis of multiple neurodegenerative conditions, including Parkinson disease, Alzheimer disease, and lysosomal storage diseases (23).

This association of inflammation and adverse events may explain why the brain seems to be governed by a unique set of immunological guidelines. A clear understanding of these "rules" may inform the design of strategies to augment protective immune responses to infection while minimizing collateral damage. Similar principles would apply to tumors in the CNS and may allow for the design of rational treatments that provide better access for $T$ cells to this relatively immune-privileged site. Conversely, in the case of 


\section{Table 1}

Modeling inflammation and cell trafficking in the CNS

\section{Model \\ Neurodegenerative \\ EAE}

SOD1 transgenic mice

Amyloid transgenic mice

\section{Malignant}

Tumor

Physical
Middle cerebral artery
occlusion
Facial nerve dichotomy
Spinal cord injury
Stab
Infectious
LCMV

Toxoplasma

Malaria

MHV

African trypanosomiasis

TMEV

Measles virus

West Nile virus

Herpes simplex virus
Model summary

A model of human MS and CNS autoimmunity. Generated by the transfer of myelin-specific T cells with or without pertussis toxin. Mice are transgenic for TCRs specific for CNS antigens such as MBP, PLP, and MOG. No model completely mimics the various human MS conditions. Spontaneous EAE can be generated using MOG transgenic mice on a RAG-deficient background.

A model of ALS characterized by the progressive loss of neurons that control muscle movement. Mutations in the SOD1 gene are associated with familial ALS. Mice deficient in SOD1 demonstrate increased muscle loss.

Mice genetically engineered to overexpress amyloid- $\beta$ are used to model Alzheimer disease. Variations include whether, and at what age, mice form plaques of amyloid and/or fibrillar amyloid.

Injection of tumor cell lines directly into the CNS can allow the modeling of CNS tumors such as gliomas. Tumors in the periphery are also used to model immune privilege (4), as the tumor environment has similar low levels of MHC, a lack of circulating lymph, and CNS trafficking.

The middle cerebral artery is the largest artery supplying the brain with blood. Occlusion models brain infarction or ischemia.

Axotomized nerve leads to Wallerian degeneration.

A measured break in the spinal cord models spinal cord injury and results in inflammation.

Acute brain injury.

Direct intracranial injection of LCMV results in a rapid, fatal inflammation with severe vasculature leakage, modeling viral meningitis, epilepsy, and stroke.

Infection with this protozoan parasite leads to chronic infection in the brain, requiring a continuous inflammatory response to prevent parasite replication and Toxoplasmic encephalitis.

Infection with Plasmodium berghei-ANKA is the main mouse model for cerebral malaria, with disease incidence varying between mouse strains.

Acute MHV infection mimics viral encephalitis. Intracranial injection of attenuated MHV strains results in encephalomyelitis, infection of astrocytes and oligodendrocytes, and a lack of sterile immunity. Chronic viral infection leads to demyelination and is therefore used as a model for MS.

Infection with human isolates of Trypanosoma brucei gambiense leads to chronic inflammation in the CNS, associated with the presence of these extracellular pathogens. In mice, sub-curative drug treatment leads to the development of a posttreatment-reactive encephalopathy that mimics disease in humans.

Intracerebral injection of TMEV results in a demyelinating pathology.

Intracerebral measles virus inoculation of mice transgenically expressing the measles virus receptor (CD46) results in fatally high virus levels and inflammation.

Subcutaneous injection into the footpad or intracranial injection of West Nile virus leads to a lethal inflammatory response.

Intracranial injection of neurotropic HSV-1 results in severe encephalitis.

There are several mouse models available that facilitate the investigation of immune cell trafficking in the brain. These can be divided into those that study mechanisms of neurodegenerative, malignant, physical, and infectious disease. ALS, amyotrophic lateral sclerosis (also known as motor neuron disease); MBP, myelin basic protein; PLP, proteolipid protein; SOD1, superoxide dismutase 1.

autoimmune conditions of the CNS, such as MS, the ideal therapeutic strategy would ameliorate the pathological response while still allowing normal immune surveillance.

The past two decades have seen remarkable advances in understanding how cells of the immune system can access the CNS, and several recent studies have highlighted the basis for immune surveillance of this organ (24-29). More recently, the ability to directly image immune cells in the context of live tissue has been possible using multi-photon microscopy. This technique, originally used to visualize neuronal morphology in the brain (30-32), has allowed the observation of fluorescently labeled immune cell populations and their migratory and interactive behavior in primary and secondary lymphoid organs, as well as peripheral tissues, during thymic selection, priming, and activation $(33,34)$. Imaging of the brain presents unique challenges because the skull prevents direct access to the tissue, but brain slices and explanted tissues can be kept viable in warmed and aerated media, and partial removal or thinning of the skull in anesthetized mice can be conducted. These techniques have allowed imaging of CNS-resident cells - neurons $(30,32,35,36)$, microglia $(37,38)$, and astrocytes $(28$, $39,40)$ - over the course of hours and days. In addition, imaging of inflamed brains and spinal cords has provided unprecedented insights into the behavior of immune cell populations in the CNS. In this review, we discuss these advances in the context of the trafficking and behavior of immune cells during protective and pathological immune responses in the CNS. 


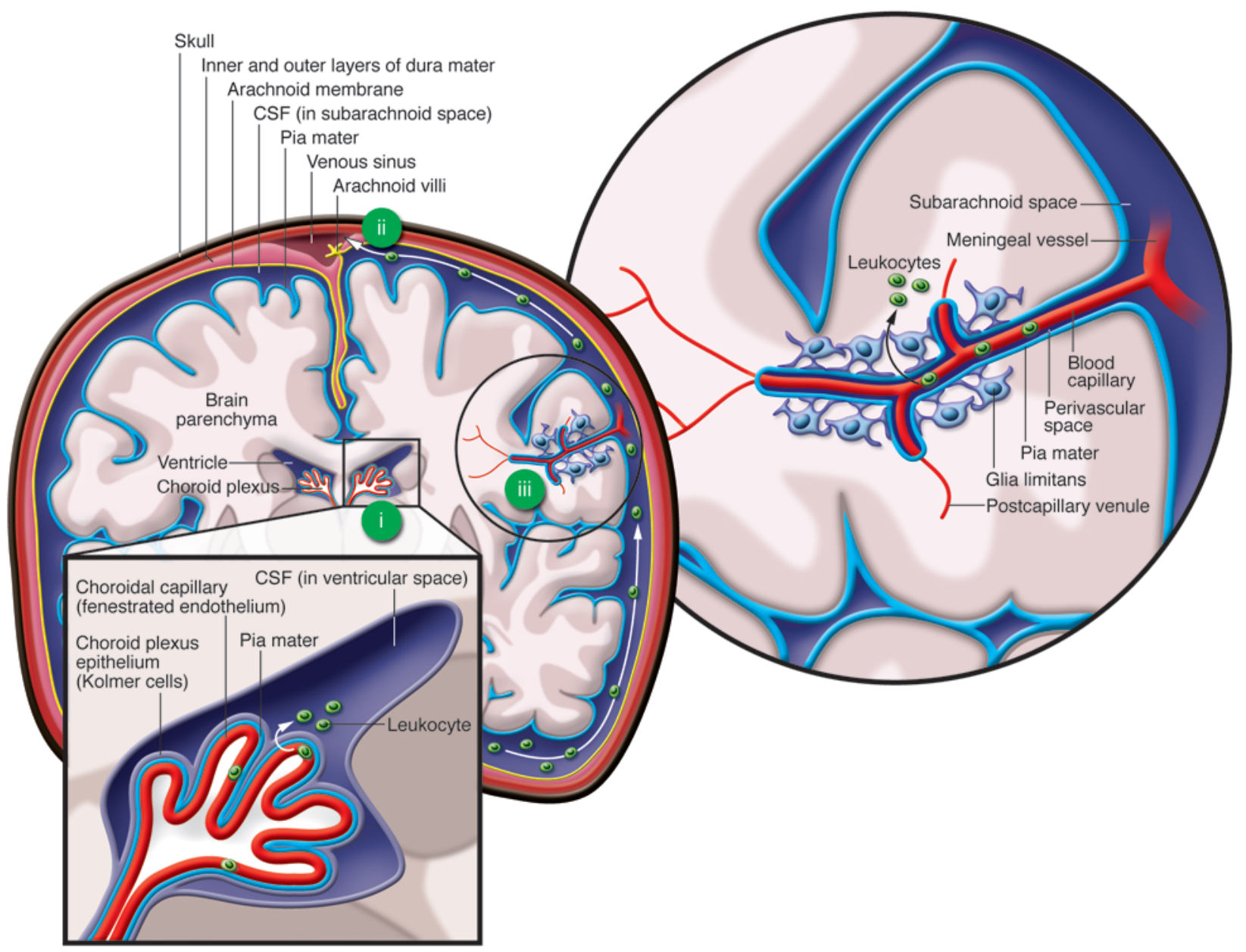

Figure 1

The structure of the brain and routes of leukocyte entry. Beneath the skull lie three membranes that enclose the parenchyma of the brain: the dura mater, the arachnoid membrane, and the pia mater. The latter two enclose the subarachnoid space. (i) Leukocytes can enter across the choroid plexus, where CSF is produced by the choroid plexus epithelium in the ventricles. CSF containing leukocytes then enters the subarachnoid space, circulates around the brain, and (ii) exits via the venous sinus to be resorbed by the blood via the arachnoid villi. (iii) Blood supply to the brain enters in the subarachnoid space over the pia mater, generating the perivascular space (or Virchow-Robin space). Main arterial branches divide into capillaries, which terminate deep within the brain, supplying the parenchyma with blood. Leukocytes can potentially enter from the blood (iii), which requires them to cross the tightly regulated vascular endothelium (i.e., the BBB: the glia limitans, the subarachnoid space, and the pia mater). Cells can adhere to the endothelium and arrest at any point during this process.

\section{Structure and routes of entry to the CNS}

The presence of the BBB, which limits the entry of cells and pathogens to the brain, in addition to the lack of obvious lymphatics in the brain, indicate that there are a limited number of portals to and from the CNS. To appreciate the barriers that exist for immune cells accessing the brain, it is important to recognize that the brain has three membranes - the dura mater (outer), the arachnoid membrane (middle), and the pia mater (inner) - that enclose the parenchyma of the CNS (Figure 1). The BBB encompasses the capillaries and postcapillary venules in the brain and spinal cord and is composed of specialized endothelial cells, linked by complex tight junctions comprised of transmembrane adhesion molecules including cadherins, junctional adhesion molecules, occludin, and claudins $(41,42)$. This structure limits the transport of specific factors and solutes, including $>98 \%$ of antibodies and small molecules, into the parenchyma, while ensuring the efflux of others $(7,43)$.
The structure of this endothelial barrier acts to limit leukocyte trafficking directly across the BBB (44). Importantly, following injury to the CNS, the activation of endothelial cells and associated cells such as astrocytes can lead to reduced tight junction integrity and formation of transendothelial cell channels $(42,45,46)$, thereby facilitating the migration of leukocytes across and through the BBB into the brain $(43,47,48)$. The migration of leukocytes into the CSF is thought to occur through the choroid plexus and into the subarachnoid space (which contains the CSF), and their migration from the blood directly into the brain parenchyma occurs across the $\mathrm{BBB}$ via the perivascular space (Figure 1). In addition to the differences in barrier properties, the vasculature itself differs between CNS compartments, and this may influence immune cell access. Thus, the capillaries of the meninges have a simple one-layer structure, whereas the postcapillary venules of the parenchyma require cells to transition across inner and outer basement membranes 


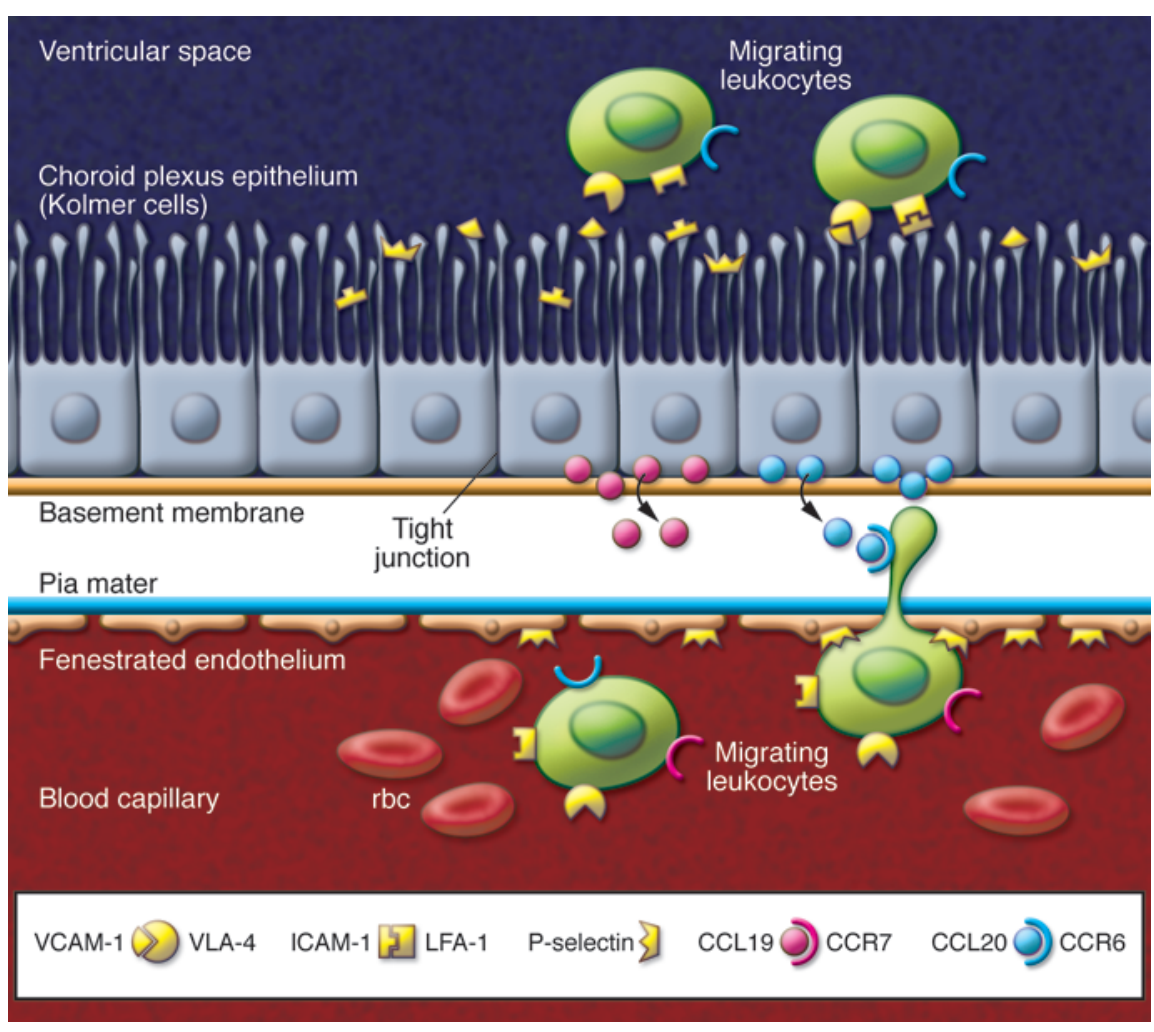

\section{Figure 2}

Immune surveillance via the choroid plexus. The choroid plexus is composed of highly invaginated loops of capillaries and pia mater that reach into the ventricles of the brain. Cells from the blood and under the influence of chemokines undergo adhesion, rolling, and diapedesis across the fenestrated capillary endothelium and pia mater of the choroid plexus. The basement membrane and tight junctions of the choroid plexus epithelium provide a further barrier, the brain-CSF barrier. These modified epithelial cells (Kolmer cells) have bulbous microvilli that secrete the CSF. Infiltrating leukocytes migrating through these cells enter the ventricles that contain CSF and circulate around the CNS. The chemokine CCL20 is expressed on the basolateral side of the choroid plexus epithelial cells, attracting CCR6-expressing CD4+ ${ }^{+}$cells. Chemokines and their receptors demonstrated to be involved in the trafficking of immune cells into the CSF are provided in Table 2. (for detailed reviews of these processes see refs. 4, 7, 41, 49). In the following sections we discuss the circumstances and mechanisms facilitating access to these specific compartments.

\section{Access to the CSF and immune surveillance}

As highlighted earlier, there are numerous pathogens that invade the CNS and/or establish latent infection with the potential to cause disease. Consequently, there is a need for immune surveillance - a continuous process whereby the peripheral immune system is able to monitor the brain for signs of infection or tissue damage. This is likely distinct from the events involved in the recruitment of various immune populations to sites of ongoing infection or inflammation. In the context of immune surveillance, the compartment that has been best studied is the CSF. The choroid plexus, which is located in the ventricles of the brain (Figure 1), has secretory epithelium that produces the CSF. Unlike the BBB, the fenestrated endothelial cells of the choroid plexus lack tight junctions that would normally limit diapedesis of leukocytes. Therefore, although immune cells still have to negotiate the tight junctions of the choroid plexus epithelium, it appears that this site is specialized to allow lymphocytes more ready access to the CSF (Figure 2). Instructively, the composition of immune cells in the blood and CSF differs. Under normal circumstances, the CSF contains few innate immune cells but a much higher percentage of memory or antigen-experienced $\mathrm{CD}^{+} \mathrm{T}$ cells than the blood (50, 51). This observation suggests that it is these cells that are specifically involved in immune surveillance.

Activated $\mathrm{T}$ cells upregulate many integrins and adhesion molecules, enabling their rolling and adhesion to vessel walls. However, deciphering which of these molecules are necessary for immune surveillance is complex. Multiple integrins, chemokine receptors, and adhesion molecules expressed on circulating and CNS-resident cells have been implicated in this process (50-52). The most likely candidates are those expressed constitutively in the CNS in the absence of ongoing inflammation. These include the adhesion molecule P-selectin $(51,53)$; the adhesion molecules vascular cell adhesion molecule 1 (VCAM1) and intercellular adhesion molecule (ICAM1), which bind to very late antigen-4 (VLA-4, also known as $\alpha 4 \beta 1$ integrin) and lymphocyte function-associated-1 (LFA-1), respectively (54); and the chemokines CCL19 and CCL20 $(29,55,56)$, all of which are constitutively expressed by epithelial cells of the choroid plexus (Figure 2). One recent study suggested a model in which, as part of normal immune surveillance, $\mathrm{CD}^{+}$ $T$ cells specific for the autoantigen myelin oligodendrocyte glycoprotein (MOG) had to express CCR6, a receptor for CCL20, for optimal access to the CSF before they could initiate experimental autoimmune encephalomyelitis (EAE) (29). However, other studies have indicated that the main contribution of CCR6 is to the priming of myelin-specific $\mathrm{CD} 4^{+} \mathrm{T}$ cells in the periphery and that CCR6 is not actually required for the ability of effector cells to access the CNS (57). Similarly, Th1 cells, which are characterized by the production of IFN- $\gamma$ and are required for resistance to multiple viral, bacterial, and parasitic pathogens that affect the CNS, do not express CCR6 and can be recruited to a site of ongoing inflammation in the CNS independently of CCR6 (29). This is consistent with reports that the majority of T cells in the CSF express CXCR3, a receptor normally associated with Th1 cells $(58,59)$. Clearly, further studies are required to determine whether pathogen-specific (or autoantigen-specific) Th1, Th2, or Th17 and/or central memory $\mathrm{T}$ cells are involved in this route of immune surveillance as well as whether there are specific trafficking requirements for Tregs as a mechanism to limit inflammation (60-62). 


\section{Accessing the meninges}

Although the ability of lymphocytes to enter the CSF has been studied in the context of autoimmune inflammation and during homeostasis, many studies on immune cell access to the meninges have been carried out in the context of infection. Inflammation of the meninges is associated with viral (herpes simplex virus [HSV], varicella zoster virus, and HIV), bacterial (Neisseria meningitidis, Streptococcus spp., Haemophilus spp., and Mycobacterium tuberculosis), fungal (Cryptococcus spp.), and parasitic (apicomplexa, trypanosomes, and amoebae) infections as well as with various noninfectious causes such as cancer or as a consequence of certain drugs or immunoglobulin therapy.

In mouse models of Theilier's murine encephalomyelitis virus (TMEV) and lymphocytic choriomeningitis virus (LCMV) infection, intracranial injection leads to leukocyte accumulation in the meninges and a fatal pathology $(63,64)$. Although it has long been known that $\mathrm{CD}^{+} \mathrm{T}$ cells are required for this to occur, it has recently been highlighted that this is independent of their cytolytic function, and intravital imaging of this process provided an unprecedented view of these events (64). In these studies, intracerebral LCMV challenge led to the infection of stromal cells in the meninges and adjacent astrocytes present in the parenchyma. This in turn resulted in the accumulation in the meninges of virusspecific $\mathrm{CD}^{+} \mathrm{T}$ cells that had a low migratory velocity. Blockade of MHC class I molecules in the subarachnoid space substantially increased the average $\mathrm{T}$ cell velocity (from approximately $3 \mu \mathrm{m} /$ min to approximately $5 \mu \mathrm{m} / \mathrm{min}$ ) and decreased both the time and the proportion of $\mathrm{T}$ cells that remained stationary, suggesting that $\mathrm{T}$ cell behavior was influenced by MHC class I-dependent recognition of infected cells. Thus, in addition to integrins and adhesion molecules, antigen recognition may be a further level of control required for $\mathrm{T}$ cell entry into the CNS and/or retention of these cells at that site $(28,65-67)$. However, meningeal LCMV-specific $\mathrm{CD}^{+} \mathrm{T}$ cells did not appear to arrest or form long-term interactions associated with efficient CTL killing of target cells $(26,68)$. Rather, these cells mediated the recruitment of neutrophils and monocytes to the meninges. Imaging of these events revealed that these latter populations crossed the meningeal endothelium in such numbers that they elicited BBB breakdown and vascular leakage, which was the main cause of death $(64,69)$. In contrast to the random migration of $\mathrm{T}$ cells that have not yet encountered antigen (70), the swarming behavior of neutrophils and monocytes at the meningeal surface involved highly directed migration, with many cells clumping, localizing to the subarachnoid space, and migrating continuously over the same area (64). Similar behavior by neutrophils in the periphery has been described during parasiteinduced inflammation, where neutrophil clusters are associated with infected cells $(71,72)$. Regardless, in the LCMV model, the leakiness of the vasculature could be observed following i.v. injection of fluorescent quantum dots and coincided with neutrophil extravasation. These studies suggest a model in which infected cells, including stromal cells of the meninges and closely associated astrocytes below the pia mater, promote the recruitment and activation of $\mathrm{CD}^{+} \mathrm{T}$ cells, likely via the release of chemokines and cytokines. These activated lymphocytes can then cross the meningeal vessel walls and encounter infected cells, which promotes T cell production of chemokines and leads to the recruitment of neutrophils and monocytes, which cause vascular leakage. Similar events occur during infection with mouse hepatitis virus (MHV) (63) and are consistent with data that neutrophils promote a breakdown in vascular integrity in the CNS (73). The distinct behavior of T cells and neutrophils in this microenvironment suggests that it might be possible to selectively alter the recruitment of individual cell populations to the CNS to prevent immune pathology, without compromising protective antipathogen responses.

\section{Migrating in the parenchyma}

Adhesion molecules. Several studies that directly visualized the molecular steps that mediate the access of T cells to various compartments associated with the CNS have been performed by imaging the superficial vessels in the meninges that are associated with the spinal cord as well as pial vessels and parenchymal branches in a variety of model systems (74-78). In the context of EAE, several reports have described the initial tethering and rolling of leukocytes along the endothelium prior to firm adhesion $(25,79)$ and migration against the blood flow (74). Similarly, intravital microscopy studies of HSV-infected mice have demonstrated increased leukocyte rolling and adhesion in the microvasculature of the pia mater of infected mice (80), and similar neutrophil behaviors in the meninges have been identified during LCMV infection (64). These observations are consistent with the idea that inflammation in the CNS, either due to autoimmune responses or infection, leads to increased expression of adhesion molecules on endothelial cells of the BBB and choroid plexus, including members of the selectin family; cell adhesion molecules of the immunoglobulin superfamily, for example, ICAM1, VCAM1, and PECAM1; and members of the integrin family (Figure 3) $(51,53,75,81-83)$. This topic has been reviewed extensively elsewhere $(41,49,76)$ and therefore is not discussed in detail here. Nevertheless, the biology of the integrin dimer VLA- 4 ( $\alpha 4 \beta 1$ integrin) and its ligand VCAM1, as well as their association with the development of MS and EAE, are particularly instructive in thinking about the need to balance immune access to the brain.

Although it is controversial as to whether VCAM1 is expressed in human vasculature, the finding that blockade of VLA-4/VCAM1 interactions delayed the onset and/or decreased the severity of EAE implicated this molecule as a target for the treatment of MS (84). This led to the clinical development of a monoclonal antibody (known as natalizumab) that targets $\alpha 4$ integrin (a component of VLA-4); natalizumab was successfully used in clinical trials to manage this condition (85). However, a small number of patients treated with this reagent developed progressive multifocal leukoencephalopathy associated with the reactivation of latent JC polyomavirus infection (20). This observation has been paralleled by the recent withdrawal of an antibody (known as efalizumab) that blocks LFA-1, which was used for the treatment of psoriasis and also led to the reactivation of JC polyomavirus in the brain (86). Whether JC polyomavirus persists in a latent form in the CNS or these events are a consequence of reactivation of the virus in peripheral tissues and subsequent spread to the CNS is unclear (87). However, recent reports that detected the presence of JCV in normal brain tissue support the former notion (88-90). Regardless, blockade of $\alpha 4$ integrin has also been shown to antagonize protective immune responses to multiple pathogens in the brain, including $T$. gondii (28), simian immunodeficiency virus-induced AIDS encephalitis (91), and Borna virus-induced progressive encephalitis (92). Other promising strategies to block cell trafficking to the CNS (77) may encounter similar problems. Despite all of these potential complications, the number of adverse events associated with natalizumab therapy has been lower than might have been predicted from studies in experimental systems, and 


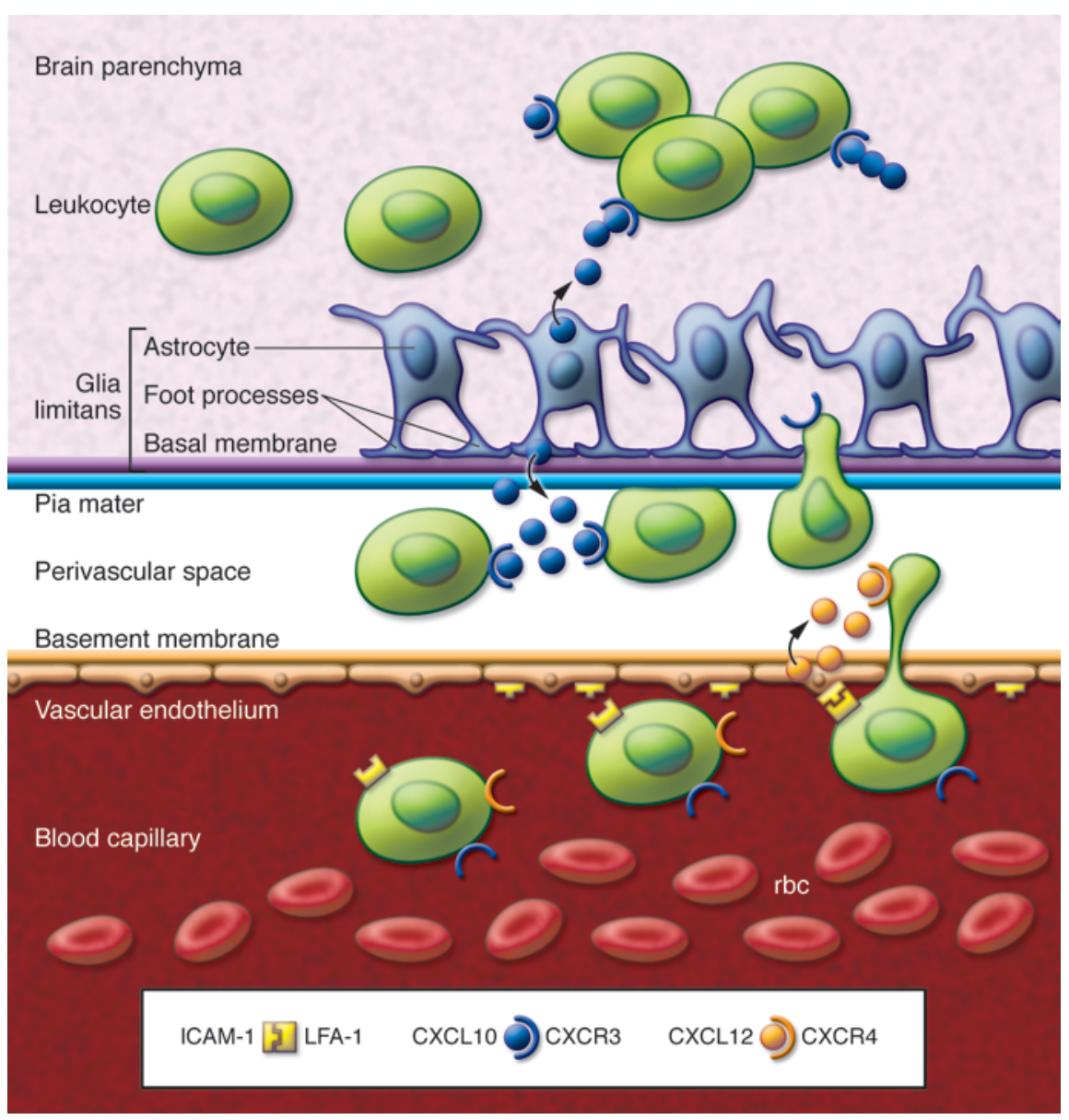

\section{Figure 3}

Leukocyte trafficking across the glia limitans into the parenchyma of the brain. Activated leukocytes expressing adhesion molecules and integrins roll and attach to the vascular endothelium. Successful diapedesis requires appropriate ligation of adhesion molecules, selectins, and integrins, signaling to both the infiltrating leukocyte and the brain endothelium. Expression of CXCL12 on the basolateral surface of endothelial cells recruits CXCR4+ T cells. However, retention of cells in the perivascular space occurs in the presence of high concentrations of CXCL10. Continued migration puts cells in contact with the glia limitans, which is composed of a highly structured wall of astrocytes. Further positive migratory signals, including chemokines, from these and surrounding cells may allow leukocyte migration into the parenchyma. this therapy continues to be used for the treatment of MS. Importantly, recent studies involving the generation of bone marrowchimeric mice in which the hematopoietic compartment lacked $\beta 1$-integrin but retained $\alpha 4 \beta 7$ integrin signaling indicated that $\mathrm{T}$ cell accumulation in the CNS during EAE required $\alpha 4 \beta 1$-integrin but that migration of granulocytes and macrophages into the CNS was independent of $\beta 1$ integrin (93). These findings highlight the potential to control the trafficking of specific immune populations and perhaps even subsets of lymphocytes into the brain.

Astrocytes and immune cell trafficking in the parenchyma. Astrocytes provide an important structural component of the BBB (94) and are thought to restrict access of immune cells to the CNS. So, after rolling along, adhering to, and finally crossing the endothelial cells of the BBB and their associated basement membrane, the migrating leukocytes reach their next barrier, the glia limitans (Figure 3). This structure surrounds the blood vessel, is composed of astrocytic foot processes, is linked to the basal membrane by the transmembrane receptor dystroglycan, and forms its own molecularly distinct basement membrane composed of laminin, fibronectin, and type IV collagen $(95,96)$. There are very few studies that have considered how leukocytes cross this second barrier, although several reports have provided evidence that production of MMPs by immune cells is required for cleavage of dystroglycan and the breakdown of BBB during EAE and neurocysticercosis associated with tapeworm infection $(96,97)$.

Reactive astrocytes are a hallmark of most inflammatory responses in the brain and this activation corresponds with increased astro- cyte numbers, changes in their morphology, and upregulated expression of glial fibrillary acidic protein, an astrocyte-specific structural protein (98). The seminal studies by Fontana et al. (99), which suggested that astrocytes could present antigen to $\mathrm{CD}^{+}$ $\mathrm{T}$ cells, highlighted the possible role of these glial cells in the immune response. Although the ability of astrocytes to present antigen through MHC class II remains controversial (100), the formation of synapses between astrocytes and antigen-specific $\mathrm{CD}^{+}$ $\mathrm{T}$ cells in vivo is consistent with their ability to present antigen through MHC class I $(101,102)$. Nevertheless, reactive astrocytes are frequently associated with migrating $\mathrm{T}$ cells and act as a source of multiple cytokines and chemokines during inflammation (103), which may actively promote cell trafficking into and within the CNS. However, in the majority of experimental systems it has not yet been defined how these interactions affect the coordination of antimicrobial immune responses.

The possible contribution of astrocytes to immune responses within the brain has been described in several settings, including those involving the targeted overexpression of cytokines - such as TNF, IFN- $\alpha$, TGF- $\beta$, IL- 6 , and IL-12 - by astrocytes, which leads to chronic inflammation and progressive neurodegeneration (104-108). More recent studies analyzing mice in which the ability of astrocytes to participate in immune function is compromised through the specific loss of a cytokine receptor such as gp130 or reduced NF- $\mathrm{KB}$ signaling, have shown that this alters the course of immune responses in the CNS (109-112). Thus, in a mouse model of spinal cord injury, astrocyte-specific inhibition of NF- $\mathrm{BB}$ (which 
Table 2

Chemokines and their receptors implicated in the trafficking of immune cells into the CNS

\begin{tabular}{|c|c|c|c|c|}
\hline $\begin{array}{l}\text { Chemokine } \\
\text { receptor }\end{array}$ & Chemokines & Disease state & Cell populations & References \\
\hline \multirow[t]{2}{*}{ CCR1 } & CCL3, CCL5 & MS/EAE & $\begin{array}{l}\text { Increases in CCL5 are found in the CSF of MS patients. Studies } \\
\text { have demonstrated a requirement for CCL5-dependent recruitment } \\
\text { of peripheral blood monocytes in a BBB model. Disease is ablated } \\
\text { in the absence of CCR1. }\end{array}$ & 119,157 \\
\hline & & Viral infection & $\begin{array}{l}\text { Blockade of CCL5 reduces antigen-specific T cell accumulation } \\
\text { during MHV infection. }\end{array}$ & 80,118 \\
\hline \multirow[t]{2}{*}{ CCR2 } & CCL2 & $\mathrm{MS} / \mathrm{EAE}$ & $\begin{array}{l}\text { CCR2-deficient mice are resistant to EAE. Glia production of CCL2 } \\
\text { recruits CCR2-expressing macrophages and dendritic cells. }\end{array}$ & $\begin{array}{l}5,120-122 \\
158-160\end{array}$ \\
\hline & & Viral infection & $\begin{array}{l}\text { CCL2 recruits CCR2-expressing macrophages, whereas CCR2 } \\
\text { expression on T cells is required to control virus } \\
\text { independently of CCL2. }\end{array}$ & $\begin{array}{l}123,161 \\
162\end{array}$ \\
\hline CCR5 & CCL4, CCL5 & MS/EAE & T cells in the CSF of MS patients are enriched for CCR5. & 116,120 \\
\hline CCR6 & CCL20 & MS/EAE & $\begin{array}{l}\text { Absence of CCR6 reduces CD4+ T cell priming and disease. } \\
\text { Choroid plexus epithelium production of CCL20 is required } \\
\text { for Th17 recruitment into the CNS. }\end{array}$ & 29,57 \\
\hline \multirow[t]{3}{*}{ CCR7 } & CCL19, CCL21 & Immune surveillance & $\begin{array}{l}\text { CCL19 is constitutively expressed in the normal brain and CSF. } \\
\text { CSF from healthy individuals has an increased concentration } \\
\text { of CCR7+ memory T cells. }\end{array}$ & $56,59,133$ \\
\hline & & MS/EAE & Increased expression of CCL19 in MS lesions and at the BBB. & $56,163,164$ \\
\hline & & T. gondii & $\begin{array}{l}\text { Increased expression of CCL21 in the CNS following infection } \\
\text { associated with migrating CD8 } 8^{+} \text {cells. }\end{array}$ & 28 \\
\hline CXCR2 & CXCL1, CXCL2 & MS/EAE & $\begin{array}{l}\text { Encephalitogenic Th17 cells induce CXCL1 and CXCL2 in the spinal } \\
\text { cord, and blockade of CXCR2 prevents disease dependent } \\
\text { on the trafficking of polymorphonuclear cells to the CNS. }\end{array}$ & 165 \\
\hline \multirow[t]{4}{*}{ CXCR3 } & $\begin{array}{l}\text { CXCL9, CXCL10, } \\
\quad \text { CXCL11 }\end{array}$ & $\mathrm{MS} / \mathrm{EAE}$ & $\begin{array}{l}\text { CXCR3 is associated with recruitment of Tregs to the brain and } \\
\text { limiting inflammation to the perivascular space. }\end{array}$ & 59,60 \\
\hline & & Immune surveillance & $\begin{array}{l}\text { Enrichment of CXCR3+ T cells in the CSF irrespective } \\
\text { of disease status. }\end{array}$ & 59 \\
\hline & & Viral infection & $\begin{array}{l}\text { Requires for CXCL9- and CXCL10-induced T cell and } \\
\text { NK cell migration into the brain to control virus replication, } \\
\text { but can be strain dependent. }\end{array}$ & $\begin{array}{l}127,128 \\
166,167\end{array}$ \\
\hline & & Cerebral malaria & $\begin{array}{l}\text { Pathological recruitment of CD8 }+\mathrm{T} \text { cells during cerebral malaria } \\
\text { is dependent on CXCR3. }\end{array}$ & 125,126 \\
\hline \multirow[t]{2}{*}{ CXCR4 } & CXCL12 & MS/EAE & $\begin{array}{l}\text { CXCL12 is constitutively expressed in the CNS by endothelial cells. } \\
\text { CXCR4 ligation inhibits recruitment of T cells and macrophages } \\
\text { to the parenchyma. }\end{array}$ & 130 \\
\hline & & Viral infection & $\begin{array}{l}\text { Blockade of CXCR4 increases T cells into the parenchyma } \\
\text { of the brain to increase control of viral replication. }\end{array}$ & 168 \\
\hline
\end{tabular}

is necessary for the activation of many cytokine genes) resulted in a reduction in the number of reactive astrocytes in the CNS, in lower levels of chemokines, and in reduced infiltration of $\mathrm{T}$ cells and macrophages (111). Consequently, this led to improved spinal cord healing. Future challenges include determining how individual cytokines, adhesion molecules, and chemokines produced by astrocytes influence the development of inflammation and the behavior of infiltrating immune cell populations.

Chemokines and migration in the parenchyma. Once cells have crossed all the membrane barriers and gained access to the parenchyma of the brain, what molecular cues guide their migration? There is an extensive list of chemokines that are either expressed constitutively or upregulated in the brain during inflammation, and infiltrating immune cells express a wide array of chemokine receptors associated with chemotaxis and/or effector function. The use of mice lacking specific chemokines or chemokine receptors and treat- ment with antagonists of these interactions has provided useful insights into which interactions are likely important in the brain. However, one of the frequently raised caveats is that this may not distinguish between their role in the development of immunity versus trafficking of cells to the CNS (compare conclusions of refs. 29 and 57). For example, the increased susceptibility of mice that lack CCL3 to viral infection in the brain may be due to poor activation and priming of dendritic cells rather than to a failure of $\mathrm{T}$ cells to traffic to and migrate within the CNS (113).

Regardless, the relevance of chemokines to immune cells in the CNS remains an area of active research and has been covered extensively in other articles $(76,114)$, and therefore we only provide a summary of their role in various model systems (Table 2 ). However, it is helpful to highlight the range of pathologies in which these molecules appear to have critical roles. The chemokine receptors CCR2 and CCR5, which are expressed on many 
monocytes and $\mathrm{T}$ cells and, despite difficulties in detecting these receptors, in MS lesions (115-117), have been implicated in CNS inflammation because blockade of their interactions leads to a reduction in inflammation in mouse models of immune-mediated demyelination (118-123). These findings are broadly consistent with the ability of chemokines to mediate their activities through chemotaxis and activation of integrins (124), but they can also have more complex effects on cell behavior. The majority of $\mathrm{T}$ cells found in the uninflamed CNS express CXCR3 (59), and this receptor has been implicated in cerebral malaria pathology $(125,126)$ and recruitment of protective CTLs during viral infection $(113,127)$. Furthermore, the recruitment of CXCR $3^{+} \mathrm{T}$ cells to neurons infected with West Nile virus has been attributed to the localized production of CXCL10 by the infected cells (128). However, the role of CXCR3 and one of its ligands, CXCL10, during EAE appears more complex (60). During this autoimmune condition, expression of CXCR3, rather than inducing a chemotactic response, is implicated in the retention of autoimmune cells and Tregs in the perivascular space (60). It is also implicated in the retention of antiviral $\mathrm{CD}^{+} \mathrm{T}$ cells during LCMV infection (129). Similarly, CXCL12, the ligand for CXCR4, is constitutively expressed in the CNS on the basolateral surface of endothelial cells and is upregulated during neuronal inflammation, and the absence of CXCR4 signaling during EAE leads to perivascular accumulation of mononuclear cells in the spinal cord (130). These studies suggest that multiple chemokines regulate access from the perivascular space to the parenchyma.

Kinetics and behavioral analysis of lymphocytes within the brain parenchyma. Related to the themes of this review, CCR7 has an important role for $\mathrm{T}$ cell and dendritic cell recruitment to the lymph node, where its ligands CCL19 and CCL21 provide motogenic signals required for efficient $\mathrm{T}$ cell and dendritic cell migration $(131,132)$. It has been suggested that expression of CCL19 in the uninflamed parenchyma has a role in immune surveillance by $\mathrm{CCR} 7^{+} \mathrm{CD} 4^{+}$memory $\mathrm{T}$ cells $(56,133)$, but this expression is elevated in MS lesions (56). CCL21 is also upregulated in other models of CNS inflammation (28), and whether these chemokines also provide motogenic signals in the parenchyma of the brain is unknown. Multiphoton microscopy of the spinal cord has been used to image the behavior of encephalitogenic cells within the white and grey matter during the induction of $\operatorname{EAE}(25,74)$. A recent detailed study has pinpointed three distinct phases for encephalitogenic $\mathrm{CD}^{+} \mathrm{T}$ cell entry into the brain: (a) arresting to leptomeningeal vessels and scanning of the luminal surface against the blood flow; (b) diapedesis and scanning of the pial membrane for antigen being presented by perivascular macrophages; and (c) successful antigen-dependent activation of T cells, triggering effector capacity and resulting in tissue invasion (74). This study challenges the notion that the choroid plexus is the major route of cell entry during EAE and solidifies data suggesting an antigen-dependent mechanism. Following activation, during the initial disease process, myelin-specific cells enter the CNS in a rapid wave and can migrate deep into the parenchyma (134). These cells could be divided into two main populations based on migratory velocities (ranging from $6-25 \mu \mathrm{m} / \mathrm{min}$ ). After entry into the perivascular space, many of the cells displayed a restrained or stationary phenotype, suggesting that they were forming long-term contacts with resident cells. This type of arrested behavior is associated with MHC/TCR interactions, although chemokines have also been implicated in mediating cell-cell interactions $(135,136)$.
Nevertheless, transfer of myelin-specific (encephalitogenic) $\mathrm{CD}^{+}$ $\mathrm{T}$ cells led to substantially more stationary cells in the brain than did the transfer of T cells not specific for CNS proteins (25). Somewhat unexpectedly, these studies revealed that $\mathrm{T}$ cell migration in this microenvironment was, at the population level, random, indicating that local migration was not regulated by chemokine gradients. Thus, although the arrest of encephalitogenic $\mathrm{CD}^{+} \mathrm{T}$ cells was antigen specific, their migration did not seem to be directional and was more like the random motility of naive $T$ cells found in the lymph node (25).

In contrast to EAE induced by the transfer of autoimmune $\mathrm{T}$ cells and intracerebral injection of LCMV, a condition with welldefined localized acute inflammatory events, mice infected with T. gondii have provided a model of chronic CNS inflammation to study the behavior of pathogen-specific $\mathrm{CD}^{+} \mathrm{T}$ cells $(28,137)$. Unlike the rapid burst of infiltration during EAE, in this experimental system, there was a continuous recruitment of antigen-specific $T$ cells that could be observed over a prolonged period of time (1-8 weeks) $(28,137)$. Various migratory behaviors including clustering and homotypic $T$ cell interactions were observed. Slowing of CD ${ }^{+} \mathrm{T}$ cells and clustering of antigen-specific cells were seen around actively replicating parasites but not latent cysts (137). With no correlation between the amount of antigen present and the confinement ratio (or meandering index) of cells, the pattern of motility seemed to represent a "search and destroy mission" to find infected cells, rather than directional migration in response to a chemokine gradient.

Despite extensive investigations, we still have a limited understanding of exactly how chemokines and other chemotactic factors contribute to the migratory behavior of $\mathrm{T}$ cells, whether in meninges, CSF, or parenchyma. Since the initial studies describing the random behavior of $\mathrm{T}$ cell migration in the lymph node, it has been established that cells follow chemokine-coated conduits and thus remain "directed" (138). Previously, intravital imaging of peripheral lymph nodes indicated that naive $\mathrm{T}$ cells migrate at speeds greater than $10 \mu \mathrm{m} / \mathrm{min}$ and are guided by conduits formed by follicular dendritic cells, fibroblastic reticular cells, and stromal cells expressing the fibroblast marker ERTR7 (138). ERTR7 ${ }^{+}$cells have also been detected at distinct but confined areas of the brain (such as the meninges, vasculature, and sulci) during inflammation caused by LCMV (64) and T. gondii infection (28). There is little understanding of the role that ERTR $7^{+}$stromal cells have in the CNS, but it is tempting to speculate that these cells promote trafficking or retain migratory leukocytes in these distinct compartments of the brain.

While the presence of a haptotaxic mechanism of migration (i.e., migration in response to chemokine bound to matrix molecules) has given rise to the idea of random exploration, it has not excluded the role of soluble chemokine gradients, nor has it been shown that gradients exist in an immobilized fashion on stromal networks (139). However, this has led to investigations into the existence of similar networks in non-lymphoid organs. Indeed, the ECM in the CNS may have a similar role to that of the constitutive structures in the lymph node $(28,138)$. Inflammation in the brain and in the periphery induces the production of ECM molecules that are known to support cell migration in the context of neural development $(140,141)$. A proteomics study demonstrated the production of many ECM molecules by astrocytes (142), and increased expression of collagen and laminins associated with myelin-containing macrophages is present in perivascular lesions 
of patients with MS (143). The use of second harmonic generation signals during multi-photon microscopy led to the visualization of a reticular network of fibers in the inflamed brain that closely associated with migrating $\mathrm{T}$ cells (28). These fibers were not present in the brains or spinal cord of naive mice but were upregulated during T. gondii infection and following EAE induction. This network may be the functional equivalent of the fibroblastic reticular cell network in the lymph node (138) and might not only provide structural support for migration but also display bound chemotactic signals for directional migration of lymphocytes. This model needs to be rigorously tested, but it may explain how lymphocytes can reach migratory velocities in this dense tissue that are comparable to those of naive $\mathrm{T}$ cells within lymph nodes.

\section{Conclusions}

It is clear that the use of intravital microscopy has advanced our understanding of the immune response in the CNS from visualizing how immune cells interact with endothelium to the more recent studies showing how immune cells behave during meningitis and parenchymal inflammation. Perhaps at one point there was the expectation that some of the adhesion molecules and chemokines that have been identified in the CNS might be specific for neuroinflammation, but to date all the molecular interactions that allow lymphocytes to access the brain are also relevant to other tissues. Thus, although natalizumab was developed specifically as a potential therapy for MS (84), it has also been approved by the FDA for the treatment of individuals with moderate to severe Crohn disease (144). However, it remains possible that there are mechanisms that provide a tissue-specific signal to lymphocytes to traffic to the brain, and there may be molecular equivalents of vitamin D or retinoic acid, which program skin- and gut-homing populations of T cells, respectively (145).

Presently, the constrained migratory behavior of $\mathrm{T}$ cells reported in EAE, LCMV infection, and toxoplasmic encephalitis has not yet been linked to effector function. Although it is reminiscent of the productive interactions between $\mathrm{T}$ cells and antigen-presenting cells in the lymph node, there is no information about whether the cytolytic activity, antigen presentation, cytokine production, or reg- ulatory mechanisms of T cells (all of which are known to occur in the CNS) are linked to these events. Similarly, whether these stalled $T$ cells interact with different accessory cell populations present in the inflamed brain has not been explored. Of particular interest is the finding that increased numbers of dendritic cells are present in the brain during neuroinflammation and have been associated with the regulation of local disease processes (146-148). Moreover, vessel-associated dendritic cells have been implicated in the regulation of T cell entry to the CNS (149), and introducing different dendritic cell subsets directly into the brain can have distinct effects on local inflammation (150). Nevertheless, there remain fundamental questions about how these professional antigen-presenting cells access and behave within the CNS. The development of strategies to deplete these populations or modify their function while in the brain will add to our understanding of how dendritic cells contribute to immune surveillance and promote or resolve ongoing local inflammation. The application of available reporters for dendritic cells (151-153), cytokine production (154), and ways to visualize cytolytic activity (155), combined with the development of new approaches such as the ability to deliver small interfering RNAs into the brain (156), should allow a dissection of how the behavior of immune cells relates to their function in the CNS. Ultimately this will help in the design of therapies that will allow for better management of the immune response in the brain.

\section{Acknowledgments}

Thanks to M.J. Carson, T.H. Harris, B. John, P. Kennedy, T. van Winkle, A. Durham, U. Von Andrian, and R. Germain for discussions at multiple times. The authors wish to acknowledge funding from the State of California (to E.H. Wilson), funding from the State of Pennsylvania and grants from the NIH (to C.A. Hunter), and grants from the National Health and Medical Research Council and New South Wales government, Australia (to W. Weninger).

Address correspondence to: Emma H. Wilson, Division of Biomedical Sciences, University of California, Riverside, Riverside, California 92521, USA. Phone: 951.827.4328; Fax: 951.827.5504; E-mail:emmaw@ucr.edu.
1. Ehrlich P. Das sauerstufbudurfnis des organismus. Eine Farbenanalytische Studie. Berlin, Germany: Hirschwald; 1885.

2. Goldmann EE. Vitalfarbung am zentralnervensystem. Abhandl Konigl preuss Akad Wiss. 1913;1:1-60.

3. Hawkins BT, Davis TP. The blood-brain barrier/ neurovascular unit in health and disease. Pharmacol Rev. 2005;57(2):173-185.

4. Mrass P, Weninger W. Immune cell migration as a means to control immune privilege: lessons from the CNS and tumors. Immunol Rev. 2006;213:195-212.

5. Ge S, Song L, Serwanski DR, Kuziel WA, Pachter JS. Transcellular transport of CCL2 across brain microvascular endothelial cells. J Neurochem. 2008; 104(5):1219-1232.

6. Galea I, Bechmann I, Perry VH. What is immune privilege (not)? Trends Immunol. 2007;28(1):12-18.

7. Bechmann I, Galea I, Perry VH. What is the bloodbrain barrier (not)? Trends Immunol. 2007;28(1):5-11.

8. Medawar PB. Immunity to homologous grafted skin; the fate of skin homografts transplanted to the brain, to subcutaneous tissue, and to the anterior chamber of the eye. Br J Exp Pathol. 1948;29(1):58-69.

9. Kim IK, Bedi DS, Denecke C, Ge X, Tullius SG. Impact of innate and adaptive immunity on rejection and tolerance. Transplantation. 2008;86(7):889-894.

10. Malipiero U, et al. TGFbeta receptor II gene deletion in leucocytes prevents cerebral vasculitis in bacterial meningitis. Brain. 2006;129(Pt 9):2404-2415.

11. Ferrari TC, Gazzinelli G, Correa-Oliveira R. Immune response and pathogenesis of neuroschistosomiasis mansoni. Acta Trop. 2008;108(2-3):83-88.

12. Siffrin V, Brandt AU, Herz J, Zipp F. New insights into adaptive immunity in chronic neuroinflammation. Adv Immunol. 2007;96:1-40.

13. Mott FW. Histological observations on the changes in the nervous system in trypanosome infections especially sleeping sickness and their relation to syphilitic lesions of the nervous system. Arch New rol. 1907;3:581-646.

14. Israelski DM, Remington JS. Toxoplasmic encephalitis in patients with AIDS. Infect Dis Clin North Am. 1988;2(2):429-445.

15. Suzuki Y, Conley FK, Remington JS. Importance of endogenous IFN-gamma for prevention of toxoplasmic encephalitis in mice. J Immunol. 1989; 143(6):2045-2050.

16. Gazzinelli R, Xu Y, Hieny S, Cheever A, Sher A. Simultaneous depletion of CD4+ and CD8+ Tlymphocytes is required to reactivate chronic infection with Toxoplasma gondii. J Immunol. 1992;149(1):175-180.

17. Du Pasquier RA, Kuroda MJ, Zheng Y, Jean-Jacques J, Letvin NL, Koralnik IJ. A prospective study demonstrates an association between JC virus-specific cytotoxic T lymphocytes and the early control of progressive multifocal leukoencephalopathy. Brain. 2004;127(Pt 9):1970-1978.

18. Mahadevan A, et al. Characterization of human immunodeficiency virus (HIV)-infected cells in infiltrates associated with CNS opportunistic infections in patients with HIV clade C infection. J Neuropathol Exp Neurol. 2007;66(9):799-808.

19. Hunter CA, Kennedy PG. Immunopathology in central nervous system human African trypanosomiasis. J Neuroimmunol. 1992;36(2-3):91-95.

20. Berger JR, Koralnik IJ. Progressive multifocal leukoencephalopathy and natalizumab--unforeseen consequences. N Engl J Med. 2005;353(4):414-416.

21. Byram SC, Carson MJ, DeBoy CA, Serpe CJ, Sanders VM, Jones KJ. CD4-positive T cell-mediated neuroprotection requires dual compartment antigen presentation. J Neurosci. 2004;24(18):4333-4339.

22. Simard AR, Soulet D, Gowing G, Julien JP, Rivest S. Bone marrow-derived microglia play a critical role in restricting senile plaque formation in Alzheimer's disease. Neuron. 2006;49(4):489-502.

23. Brochard V, et al. Infiltration of CD4+ lymphocytes into the brain contributes to neurodegeneration in a mouse model of Parkinson disease. J Clin Invest. 2009; 119(1):182-192.

24. Davalos D, et al. Stable in vivo imaging of densely 
populated glia, axons and blood vessels in the mouse spinal cord using two-photon microscopy. J Neurosci Methods. 2008;169(1):1-7.

25. Kawakami N, Nagerl UV, Odoardi F, Bonhoeffer T, Wekerle H, Flugel A. Live imaging of effector cell trafficking and autoantigen recognition within the unfolding autoimmune encephalomyelitis lesion. J Exp Med. 2005;201(11):1805-1814.

26. Mrass $P$, et al. Random migration precedes stable target cell interactions of tumor-infiltrating T cells. J Exp Med. 2006;203(12):2749-2761.

27. Kim MG, Chen C, Flomerfelt FA, Germain RN, Schwartz RH. A subtractive PCR-based cDNA library made from fetal thymic stromal cells. J Immunol Methods. 1998;213(2):169-182.

28. Wilson EH, et al. Behavior of parasite-specific effector CD8+ T cells in the brain and visualization of a kinesis-associated system of reticular fibers. Immunity. 2009;30(2):300-311.

29. Reboldi A, et al. C-C chemokine receptor 6-regulated entry of $\mathrm{TH}-17$ into the $\mathrm{CNS}$ through the choroid plexus is required for the initiation of EAE. Nat Immunol. 2009;10:514-523.

30. Denk W. Two-photon scanning photochemical microscopy: mapping ligand-gated ion channel distributions. Proc Natl Acad Sci U S A. 1994; 91(14):6629-6633.

31. Potter SM. Vital imaging: two photons are better than one. Curr Biol. 1996;6(12):1595-1598.

32. Chen BE, Lendvai B, Nimchinsky EA, Burbach B, Fox K, Svoboda K. Imaging high-resolution structure of GFP-expressing neurons in neocortex in vivo. Learn Mem. 2000;7(6):433-441.

33. Bousso P, Bhakta NR, Lewis RS, Robey E. Dynamics of thymocyte-stromal cell interactions visualized by two-photon microscopy. Science. 2002; 296(5574):1876-1880.

34. Bajenoff M, Germain RN. Seeing is believing: a focus on the contribution of microscopic imaging to our understanding of immune system function. Eur J Immunol. 2007;(37 suppl 1):S18-S33.

35. Zhang ZG, et al. A model of mini-embolic stroke offers measurements of the neurovascular unit response in the living mouse. Stroke. 2005; 36(12):2701-2704.

36. Holtmaat A, De Paola V, Wilbrecht L, Knott GW. Imaging of experience-dependent structural plasticity in the mouse neocortex in vivo. Behav Brain Res. 2008;192(1):20-25.

37. Davalos D, et al. ATP mediates rapid microglial response to local brain injury in vivo. Nat Neurosci. 2005;8(6):752-758.

38. Haynes SE, et al. The P2Y12 receptor regulates microglial activation by extracellular nucleotides. Nat Neurosci. 2006;9(12):1512-1519.

39. Ding S, et al. Enhanced astrocytic Ca2+ signals contribute to neuronal excitotoxicity after status epilepticus. J Neurosci. 2007;27(40):10674-10684.

40. Ding S, Wang T, Cui W, Haydon PG. Photothrombosis ischemia stimulates a sustained astrocytic $\mathrm{Ca}(2+)$ signaling in vivo. Glia. 2009;57(7):767-776.

41. Engelhardt B, Ransohoff RM. The ins and outs of T-lymphocyte trafficking to the CNS: anatomical sites and molecular mechanisms. Trends Immunol. 2005;26(9):485-495.

42. Stamatovic SM, Keep RF, Andjelkovic AV. Brain endothelial cell-cell junctions: how to "open" the blood brain barrier. Curr Neuropharmacol. 2008; 6(3):179-192

43. Wolburg H, Wolburg-Buchholz K, Engelhardt B. Diapedesis of mononuclear cells across cerebral venules during experimental autoimmune encephalomyelitis leaves tight junctions intact. Acta Neuropathol. 2005;109(2):181-190.

44. Huber JD, Egleton RD, Davis TP. Molecular physiology and pathophysiology of tight junctions in the blood-brain barrier. Trends Neurosci. 2001; 24(12):719-725.
45. Lossinsky AS, Buttle KF, Pluta R, Mossakowski MJ, Wisniewski HM. Immunoultrastructural expression of intercellular adhesion molecule- 1 in endothelial cell vesiculotubular structures and vesiculovacuolar organelles in blood-brain barrier development and injury. Cell Tissue Res. 1999;295(1):77-88.

46. Lossinsky AS, Shivers RR. Structural pathways for macromolecular and cellular transport across the blood-brain barrier during inflammatory conditions. Review. Histol Histopathol. 2004;19(2):535-564.

47. Raine CS, Cannella B, Duijvestijn AM, Cross AH. Homing to central nervous system vasculature by antigen-specific lymphocytes. II. Lymphocyte/endothelial cell adhesion during the initial stages of autoimmune demyelination. Lab Invest. 1990;63(4):476-489.

48. Wolburg H, Wolburg-Buchholz K, Engelhardt B. Involvement of tight junctions during transendothelial migration of mononuclear cells in experimental autoimmune encephalomyelitis. Ernst Schering Res Found Workshop. 2004;(47):17-38.

49. Ransohoff RM, Kivisakk P, Kidd G. Three or more routes for leukocyte migration into the central nervous system. Nat Rev Immunol. 2003;3(7):569-581.

50. Kivisakk P, Tucky B, Wei T, Campbell JJ, Ransohoff RM. Human cerebrospinal fluid contains CD4+ memory $\mathrm{T}$ cells expressing gut- or skin-specific trafficking determinants: relevance for immunotherapy. BMC Immunol. 2006;7:14.

51. Kivisakk P, et al. Human cerebrospinal fluid central memory CD4+ T cells: evidence for trafficking through choroid plexus and meninges via P-selectin. Proc Natl Acad Sci U S A. 2003;100(14):8389-8394.

52. Provencio JJ, Kivisakk P, Tucky BH, Luciano MG, Ransohoff RM. Comparison of ventricular and lumbar cerebrospinal fluid $\mathrm{T}$ cells in non-inflammatory neurological disorder (NIND) patients. J Neuroimmunol. 2005;163(1-2):179-184.

53. Carrithers MD, Visintin I, Viret C, Janeway CS Jr. Role of genetic background in P selectin-dependent immune surveillance of the central nervous system. J Neuroimmunol. 2002;129(1-2):51-57.

54. Wolburg K, Gerhardt H, Schulz M, Wolburg H, Engelhardt B. Ultrastructural localization of adhesion molecules in the healthy and inflamed choroid plexus of the mouse. Cell Tissue Res. 1999; 296(2):259-269.

55. Krumbholz M, et al. Chemokines in multiple sclerosis: CXCL12 and CXCL13 up-regulation is differentially linked to CNS immune cell recruitment. Brain. 2006;129(Pt 1):200-211.

56. Krumbholz M, et al. CCL19 is constitutively expressed in the CNS, up-regulated in neuroinflammation, active and also inactive multiple sclerosis lesions. J Neuroimmunol. 2007;190(1-2):72-79.

57. Liston A, et al. Inhibition of CCR6 function reduces the severity of experimental autoimmune encephalomyelitis via effects on the priming phase of the immune response. J Immunol. 2009; 182(5):3121-3130

58. Balashov KE, Rottman JB, Weiner HL, Hancock WW. CCR5 $(+)$ and CXCR3 $(+)$ T cells are increased in multiple sclerosis and their ligands MIP-1alpha and IP-10 are expressed in demyelinating brain lesions. Proc Natl Acad Sci U S A. 1999;96(12):6873-6878.

59. Kivisakk P, et al. T-cells in the cerebrospinal fluid express a similar repertoire of inflammatory chemokine receptors in the absence or presence of CNS inflammation: implications for CNS trafficking. Clin Exp Immunol. 2002;129(3):510-518.

60. Muller M, et al. CXCR3 signaling reduces the severity of experimental autoimmune encephalomyelitis by controlling the parenchymal distribution of effector and regulatory $\mathrm{T}$ cells in the central nervous system. J Immunol. 2007;179(5):2774-2786.

61. Steeg C, Adler G, Sparwasser T, Fleischer B, Jacobs $\mathrm{T}$. Limited role of CD4+Foxp3+ regulatory T cells in the control of experimental cerebral malaria. J Immunol. 2009;183(11):7014-7022.
62. Villares R, et al. CCR6 regulates EAE pathogenesis by controlling regulatory $\mathrm{CD} 4+\mathrm{T}$-cell recruitment to target tissues. Eur J Immunol. 2009;39(6):1671-1681.

63. Zhou J, Stohlman SA, Hinton DR, Marten NW. Neutrophils promote mononuclear cell infiltration during viral-induced encephalitis. J Immunol. 2003; 170(6):3331-3336.

64. Kim JV, Kang SS, Dustin ML, McGavern DB. Myelomonocytic cell recruitment causes fatal CNS vascular injury during acute viral meningitis. Nature. 2009;457(7226):191-195.

65. Ling C, Sandor M, Fabry Z. In situ processing and distribution of intracerebrally injected OVA in the CNS. J Neuroimmunol. 2003;141(1-2):90-98.

66. Ling C, Sandor M, Suresh M, Fabry Z. Traumatic injury and the presence of antigen differentially contribute to T-cell recruitment in the CNS. J Neurosci. 2006;26(3):731-741.

67. Galea I, Bernardes-Silva M, Forse PA, van Rooijen N, Liblau RS, Perry VH. An antigen-specific pathway for CD8 T cells across the blood-brain barrier. J Exp Med. 2007;204(9):2023-2030.

68. Stinchcombe JC, Griffiths GM. Secretory mechanisms in cell-mediated cytotoxicity. Annu Rev Cell Dev Biol. 2007;23:495-517.

69. Suidan GL, McDole JR, Chen Y, Pirko I, Johnson AJ. Induction of blood brain barrier tight junction protein alterations by CD8 T cells. PLoS ONE. 2008; 3(8):e3037.

70. Miller MJ, Hejazi AS, Wei SH, Cahalan MD, Parker I. $T$ cell repertoire scanning is promoted by dynamic dendritic cell behavior and random T cell motility in the lymph node. Proc Natl Acad Sci U S A. 2004; 101(4):998-1003.

71. Chtanova T, et al. Dynamics of neutrophil migration in lymph nodes during infection. Immunity. 2008;29(3):487-496.

72. Peters NC, et al. In vivo imaging reveals an essential role for neutrophils in leishmaniasis transmitted by sand flies. Science. 2008;321(5891):970-974.

73. Wedmore CV, Williams TJ. Control of vascular permeability by polymorphonuclear leukocytes in inflammation. Nature. 1981;289(5799):646-650.

74. Bartholomaus I, et al. Effector T cell interactions with meningeal vascular structures in nascent autoimmune CNS lesions. Nature. 2009;462(7269):94-98.

75. Piccio L, et al. Efficient recruitment of lymphocytes in inflamed brain venules requires expression of cutaneous lymphocyte antigen and fucosyltransferase-VII. J Immunol. 2005;174(9):5805-5813.

76. Constantin G. Chemokine signaling and integrin activation in lymphocyte migration into the inflamed brain. J Neuroimmunol. 2008;198(1-2):20-26.

77. Lapointe BM, Herx LM, Gill V, Metz LM, Kubes P. IVIg therapy in brain inflammation: etiologydependent differential effects on leucocyte recruitment. Brain. 2004;127(Pt 12):2649-2656.

78. Kubes P, Ward PA. Leukocyte recruitment and the acute inflammatory response. Brain Pathol. 2000; 10(1):127-135.

79. Flugel A, et al. Migratory activity and functional changes of green fluorescent effector cells before and during experimental autoimmune encephalomyelitis. Immunity. 2001;14(5):547-560.

80. Vilela MC, et al. Traffic of leukocytes in the central nervous system is associated with chemokine up-regulation in a severe model of herpes simplex encephalitis: an intravital microscopy study. Neurosci Lett. 2008;445(1):18-22.

81. Carrithers MD, Visintin I, Kang SJ, Janeway CA Jr. Differential adhesion molecule requirements for immune surveillance and inflammatory recruitment. Brain. 2000;123 (Pt 6):1092-1101.

82. Verma S, et al. West Nile virus infection modulates human brain microvascular endothelial cells tight junction proteins and cell adhesion molecules: Transmigration across the in vitro blood-brain barrier. Virology. 2009;385(2):425-433. 
83. Deckert-Schluter M, Schluter D, Hof H, Wiestler OD, Lassmann H. Differential expression of ICAM-1, VCAM-1 and their ligands LFA-1, Mac-1, CD43, VLA-4, and MHC class II antigens in murine Toxoplasma encephalitis: a light microscopic and ultrastructural immunohistochemical study. J Neuropathol Exp Neurol. 1994;53(5):457-468.

84. Yednock TA, Cannon C, Fritz LC, Sanchez-Madrid F, Steinman L, Karin N. Prevention of experimental autoimmune encephalomyelitis by antibodies against alpha 4 beta 1 integrin. Nature. 1992; 356(6364):63-66

85. Engelhardt B, Kappos L. Natalizumab: targeting alpha4-integrins in multiple sclerosis. Neurodegener Dis. 2008;5(1):16-22

86. Molloy ES, Calabrese LH. Therapy: Targeted but not trouble-free: efalizumab and PML. Nat Rev Rheumatol. 2009;5(8):418-419.

87. Major EO. Reemergence of PML in natalizumabtreated patients-new cases, same concerns. $N$ EnglJ Med. 2009;361(11):1041-1043.

88. Focosi D, Kast RE, Maggi F, Ceccherini-Nelli L, Petrini M. JC virus DNA in healthy brain tissue: a challenge for progressive multifocal leukoencephalopathy diagnosis. Ann Neurol. 2009;65(2):230.

89. Focosi D, Kast RE, Maggi F, Ceccherini-Nelli L, Petrini M. Lymphotropic polyomavirus and progressive multifocal leukoencephalopathy. J Clin Microbiol. 2009;47(1):284

90. Koralnik IJ, Boden D, Mai VX, Lord CI, Letvin NL. JC virus DNA load in patients with and without progressive multifocal leukoencephalopathy. Newrology. 1999;52(2):253-260.

91. Sasseville VG, Newman W, Brodie SJ, Hesterberg P, Pauley D, Ringler DJ. Monocyte adhesion to endothelium in simian immunodeficiency virusinduced AIDS encephalitis is mediated by vascular cell adhesion molecule-1/alpha 4 beta 1 integrin interactions. Am J Pathol. 1994;144(1):27-40.

92. Planz O, Bilzer T, Stitz L. Immunopathogenic role of T-cell subsets in Borna disease virus-induced progressive encephalitis. J Virol. 1995;69(2):896-903.

93. Bauer $M$, et al. Beta1 integrins differentially control extravasation of inflammatory cell subsets into the CNS during autoimmunity. Proc Natl Acad SciUS A. 2009;106(6):1920-1925.

94. Willis CL, Davis TP. Chronic inflammatory pain and the neurovascular unit: a central role for glia in maintaining BBB integrity? Curr Pharm Des. 2008; 14(16):1625-1643

95. Sixt M, Engelhardt B, Pausch F, Hallmann R, Wendler O, Sorokin LM. Endothelial cell laminin isoforms, laminins 8 and 10, play decisive roles in $\mathrm{T}$ cell recruitment across the blood-brain barrier in experimental autoimmune encephalomyelitis. J Cell Biol. 2001;153(5):933-946.

96. Agrawal S, et al. Dystroglycan is selectively cleaved at the parenchymal basement membrane at sites of leukocyte extravasation in experimental autoimmune encephalomyelitis. J Exp Med. 2006; 203(4):1007-1019

97. Alvarez JI, Teale JM. Multiple expression of matrix metalloproteinases in murine neurocysticercosis: Implications for leukocyte migration through multiple central nervous system barriers. Brain Res. 2008; 1214:145-158.

98. Escartin C, Bonvento G. Targeted activation of astrocytes: a potential neuroprotective strategy. Mol Neurobiol. 2008;38(3):231-241.

99. Fontana A, Fierz W, Wekerle H. Astrocytes present myelin basic protein to encephalitogenic T-cell lines. Nature. 1984;307(5948):273-276.

100.Bo L, Mork S, Kong PA, Nyland H, Pardo CA Trapp BD. Detection of MHC class II-antigens on macrophages and microglia, but not on astrocytes and endothelia in active multiple sclerosis lesions. J Neuroimmunol. 1994;51(2):135-146.

101. Barcia C, et al. T cells' immunological synapses induce polarization of brain astrocytes in vivo and in vitro: a novel astrocyte response mechanism to cellular injury. PLoS ONE. 2008;3(8):e2977.

102.Barcia C, Wawrowsky K, Barrett RJ, Liu C, Castro MG, Lowenstein PR. In vivo polarization of IFNgamma at Kupfer and non-Kupfer immunological synapses during the clearance of virally infected brain cells. J Immunol. 2008;180(3):1344-1352.

103. Nair A, Frederick TJ, Miller SD. Astrocytes in multiple sclerosis: a product of their environment. Cell Mol Life Sci. 2008;65(17):2702-2720.

104. Campbell IL, et al. Neurologic disease induced in transgenic mice by cerebral overexpression of interleukin 6 . Proc Natl Acad Sci US A. 1993;90(21):10061-10065.

105. Akwa Y, et al. Transgenic expression of IFN-alpha in the central nervous system of mice protects against lethal neurotropic viral infection but induces inflammation and neurodegeneration. I Immunol. 1998;161(9):5016-5026

106.Pagenstecher A, Lassmann S, Carson MJ, Kincaid CL, Stalder AK, Campbell IL. Astrocyte-targeted expression of IL-12 induces active cellular immune responses in the central nervous system and modulates experimental allergic encephalomyelitis. J Immunol. 2000;164(9):4481-4492.

107. Wyss-Coray T, Borrow P, Brooker MJ, Mucke L. Astroglial overproduction of TGF-beta 1 enhances inflammatory central nervous system disease in transgenic mice. J Neuroimmunol. 1997;77(1):45-50.

108. Krishnamoorthy G, Holz A, Wekerle H. Experimental models of spontaneous autoimmune disease in the central nervous system. J Mol Med. 2007; 85(11):1161-1173.

109. Sofroniew MV. Reactive astrocytes in neural repai and protection. Neuroscientist. 2005;11(5):400-407.

110.Drogemuller K, et al. Astrocyte gp130 expression is critical for the control of Toxoplasma encephalitis. J Immunol. 2008;181(4):2683-2693.

111. Brambilla R, et al. Inhibition of astroglial nuclear factor kappaB reduces inflammation and improves functional recovery after spinal cord injury. $J$ Exp Med. 2005;202(1):145-156.

112. Brambilla R, et al. Transgenic inhibition of astroglial NF-kappaB improves functional outcome in experimental autoimmune encephalomyelitis by suppressing chronic central nervous system inflammation. J Immunol. 2009;182(5):2628-2640.

113.Trifilo MJ, Lane TE. The CC chemokine ligand 3 regulates $\mathrm{CD} 11 \mathrm{c}+\mathrm{CD} 11 \mathrm{~b}+\mathrm{CD} 8 \mathrm{alpha}$ - dendritic cell maturation and activation following viral infection of the central nervous system: implications for a role in T cell activation. Virology. 2004;327(1):8-15

114. Cardona AE, Li M, Liu L, Savarin C, Ransohoff RM. Chemokines in and out of the central nervous system: much more than chemotaxis and inflammation. J Lenkoc Biol. 2008;84(3):587-594.

115. Mahad D, et al. Modulating CCR2 and CCL2 at the blood-brain barrier: relevance for multiple sclerosis pathogenesis. Brain. 2006;129(Pt 1):212-223.

116. Sorensen TL, et al. Expression of specific chemokines and chemokine receptors in the central nervous system of multiple sclerosis patients. $J$ Clin Invest. 1999;103(6):807-815.

117. Sorensen TL, Ransohoff RM, Strieter RM, Sellebjerg F. Chemokine CCL2 and chemokine receptor CCR2 in early active multiple sclerosis. Eur J Neurol. 2004;11(7):445-449.

118.Glass WG, Hickey MJ, Hardison JL, Liu MT, Manning JE, Lane TE. Antibody targeting of the CC chemokine ligand 5 results in diminished leukocyte infiltration into the central nervous system and reduced neurologic disease in a viral model of multiple sclerosis. J Immunol. 2004;172(7):4018-4025.

119.Ubogu EE, Callahan MK, Tucky BH, Ransohoff RM. Determinants of CCL5-driven mononuclear cell migration across the blood-brain barrier. Implications for therapeutically modulating neuroinflammation. J Neuroimmunol. 2006;179(1-2):132-144.
120. dos Santos AC, Barsante MM, Arantes RM, Bernard CC, Teixeira MM, Carvalho-Tavares J. CCL2 and CCL5 mediate leukocyte adhesion in experimental autoimmune encephalomyelitis--an intravital microscopy study. J Neuroimmunol. 2005;162(1-2):122-129.

121.Dogan RN, Elhofy A, Karpus WJ. Production of CCL2 by central nervous system cells regulates development of murine experimental autoimmune encephalomyelitis through the recruitment of TNFand iNOS-expressing macrophages and myeloid dendritic cells. J Immunol. 2008;180(11):7376-7384.

122. Brini E, et al. Administration of a monomeric CCL2 variant to EAE mice inhibits inflammatory cell recruitment and protects from demyelination and axonal loss. J Neuroimmunol. 2009;209(1-2):33-39.

123. Held KS, Chen BP, Kuziel WA, Rollins BJ, Lane TE. Differential roles of CCL2 and CCR2 in host defense to coronavirus infection. Virology. 2004; 329(2):251-260.

124.von Andrian UH, Mackay CR. T-cell function and migration. Two sides of the same coin. NEngl J Med. 2000;343(14):1020-1034.

125. Campanella GS, et al. Chemokine receptor CXCR3 and its ligands CXCL9 and CXCL10 are required for the development of murine cerebral malaria. Proc Natl Acad Sci U S A. 2008;105(12):4814-4819.

126.Srivastava K, et al. Platelet factor 4 mediates inflammation in experimental cerebral malaria. Cell Host Microbe. 2008;4(2):179-187.

127. Muse M, Kane JA, Carr DJ, Farber JM, Lane TE. Insertion of the CXC chemokine ligand 9 (CXCL9) into the mouse hepatitis virus genome results in protection from viral-induced encephalitis and hepatitis. Virology. 2008;382(2):132-144.

128.Zhang B, Chan YK, Lu B, Diamond MS, Klein RS. CXCR3 mediates region-specific antiviral $T$ cell trafficking within the central nervous system during West Nile virus encephalitis. J Immunol. 2008;180(4):2641-2649.

129. Christensen JE, et al. Efficient T-cell surveillance of the CNS requires expression of the CXC chemokine receptor 3. J Neurosci. 2004;24(20):4849-4858.

130.McCandless EE, Wang Q, Woerner BM, Harper JM, Klein RS. CXCL12 limits inflammation by localizing mononuclear infiltrates to the perivascular space during experimental autoimmune encephalomyelitis. J Immunol. 2006;177(11):8053-8064.

131. Worbs T, Mempel TR, Bolter J, von Andrian UH, Forster R. CCR7 ligands stimulate the intranodal motility of T lymphocytes in vivo. J Exp Med. 2007; 204(3):489-495.

132. Okada T, Cyster JG. CC chemokine receptor 7 contributes to Gi-dependent $\mathrm{T}$ cell motility in the lymph node. J Immunol. 2007;178(5):2973-2978.

133. Kivisakk P, et al. Expression of CCR7 in multiple sclerosis: implications for CNS immunity. Ann Neurol. 2004;55(5):627-638

134.Flugel A, Odoardi F, Nosov M, Kawakami N. Autoaggressive effector $\mathrm{T}$ cells in the course of experimental autoimmune encephalomyelitis visualized in the light of two-photon microscopy. J Neuroimmunol. 2007;191(1-2):86-97.

135. Klein RS. Regulation of neuroinflammation: the role of CXCL10 in lymphocyte infiltration during autoimmune encephalomyelitis. J Cell Biochem. 2004;92(2):213-222.

136. Molon B, et al. $\mathrm{T}$ cell costimulation by chemokine receptors. Nat Immunol. 2005;6(5):465-471.

137. Schaeffer M, et al. Dynamic imaging of T cell-parasite interactions in the brains of mice chronically infected with Toxoplasma gondii. J Immunol. 2009; 182(10):6379-6393

138. Bajenoff M, et al. Stromal cell networks regulate lymphocyte entry, migration, and territoriality in lymph nodes. Immunity. 2006;25(6):989-1001.

139. Bromley SK, Mempel TR, Luster AD. Orchestrating the orchestrators: chemokines in control of T cell traffic. Nat Immunol. 2008;9(9):970-980. 
140. Fitch MT, Silver J. CNS injury, glial scars, and inflammation: Inhibitory extracellular matrices and regeneration failure. Exp Neurol. 2008;209(2):294-301.

141.Heck N, et al. Evidence for distinct leptomeningeal cell-dependent paracrine and EGF-linked autocrine regulatory pathways for suppression of fibrillar collagens in astrocytes. Mol Cell Neurosci. 2007;36(1):71-85.

142. Keene SD, et al. Mass spectrometric and computational analysis of cytokine-induced alterations in the astrocyte secretome. Proteomics. 2009;9(3):768-782.

143.van Horssen J, Bo L, Vos CM, Virtanen I, de Vries HE. Basement membrane proteins in multiple sclerosis-associated inflammatory cuffs: potential role in influx and transport of leukocytes. J Neuropathol Exp Neurol. 2005;64(8):722-729.

144.Sandborn WJ, et al. Natalizumab induction and maintenance therapy for Crohn's disease. $N \mathrm{EnglJ}$ Med. 2005;353(18):1912-1925.

145. Mora JR, Iwata M, von Andrian UH. Vitamin effects on the immune system: vitamins A and D take centre stage. Nat Rev Immunol. 2008;8(9):685-698.

146. Lauterbach H, Zuniga EI, Truong P, Oldstone MB, McGavern DB. Adoptive immunotherapy induces CNS dendritic cell recruitment and antigen presentation during clearance of a persistent viral infection. J Exp Med. 2006;203(8):1963-1975.

147. Alvarez D, Vollmann EH, von Andrian UH. Mechanisms and consequences of dendritic cell migration. Immunity. 2008;29(3):325-342.

148. Bailey SL, Schreiner B, McMahon EJ, Miller SD. CNS myeloid DCs presenting endogenous myelin peptides 'preferentially' polarize $\mathrm{CD} 4+\mathrm{T}(\mathrm{H})-17$ cells in relapsing EAE. Nat Immunol. 2007;8(2):172-180.

149.Greter M, et al. Dendritic cells permit immune invasion of the CNS in an animal model of multiple sclerosis. Nat Med. 2005;11(3):328-334.

150.Zozulya AL, Reinke E, Baiu DC, Karman J, Sandor M, Fabry Z. Dendritic cell transmigration through brain microvessel endothelium is regulated by MIP- 1alpha chemokine and matrix metalloproteinases. J Immunol. 2007;178(1):520-529.

151.Lechmann M, Shuman N, Wakeham A, Mak TW. The CD83 reporter mouse elucidates the activity of the CD83 promoter in B, T, and dendritic cell populations in vivo. Proc Natl Acad Sci U S A. 2008; 105(33):11887-11892.

152.Hon H, Jacob J. Tracking dendritic cells in vivo: insights into DC biology and function. Immunol Res. 2004;29(1-3):69-80.

153.Belz GT, et al. The CD8alpha(+) dendritic cell is responsible for inducing peripheral self-tolerance to tissue-associated antigens. J Exp Med. 2002; 196(8):1099-1104.

154.Mohrs M, Shinkai K, Mohrs K, Locksley RM. Analysis of type 2 immunity in vivo with a bicistronic IL-4 reporter. Immunity. 2001;15(2):303-311.

155. Mempel TR, Bauer CA. Intravital imaging of CD8(+) $\mathrm{T}$ cell function in cancer. Clin Exp Metastasis. 2008; 26(4):311-327.

156. Kumar $\mathrm{P}$, et al. Transvascular delivery of small interfering RNA to the central nervous system. Nature. 2007;448(7149):39-43.

157. Rottman JB, Slavin AJ, Silva R, Weiner HL, Gerard CG, Hancock WW. Leukocyte recruitment during onset of experimental allergic encephalomyelitis is CCR1 dependent. Eur IImmunol. 2000;30(8):2372-2377.

158.Glabinski AR, Bielecki B, O’Bryant S, Selmaj K, Ransohoff RM. Experimental autoimmune encephalomyelitis: CC chemokine receptor expression by trafficking cells. J Autoimmun. 2002;19(4):175-181.

159. Elhofy A, et al. Transgenic expression of CCL2 in the central nervous system prevents experimental autoimmune encephalomyelitis. J Leukoc Biol. 2005; 77(2):229-237.

160. Izikson L, Klein RS, Charo IF, Weiner HL, Luster AD. Resistance to experimental autoimmune encephalomyelitis in mice lacking the CC chemokine receptor (CCR)2.J Exp Med. 2000;192(7):1075-1080.

161.Getts DR, et al. Ly6c+ “inflammatory monocytes” are microglial precursors recruited in a pathogenic manner in West Nile virus encephalitis. J Exp Med. 2008; 205(10):2319-2337.

162. Bennett JL, Elhofy A, Charo I, Miller SD, Dal Canto MC, Karpus WJ. CCR2 regulates development of Theiler's murine encephalomyelitis virus-induced demyelinating disease. Viral Immunol. 2007; 20(1):19-33.

163.Alt C, Laschinger M, Engelhardt B. Functional expression of the lymphoid chemokines CCL19 (ELC) and CCL 21 (SLC) at the blood-brain barrier suggests their involvement in G-protein-dependent lymphocyte recruitment into the central nervous system during experimental autoimmune encephalomyelitis. Eur J Immunol. 2002;32(8):2133-2144.

164.Columba-Cabezas S, Serafini B, Ambrosini E, Aloisi F. Lymphoid chemokines CCL19 and CCL21 are expressed in the central nervous system during experimental autoimmune encephalomyelitis: implications for the maintenance of chronic neuroinflammation. Brain Pathol. 2003;13(1):38-51.

165. Carlson T, Kroenke M, Rao P, Lane TE, Segal B. The Th17-ELR+ CXC chemokine pathway is essential for the development of central nervous system autoimmune disease. J Exp Med. 2008;205(4):811-823.

166. Hofer M, Hausmann J, Staeheli P, Pagenstecher A. Cerebral expression of interleukin-12 induces neurological disease via differential pathways and recruits antigen-specific $\mathrm{T}$ cells in virus-infected mice. Am J Pathol. 2004;165(3):949-958.

167. Trifilo MJ, et al. CXC chemokine ligand 10 controls viral infection in the central nervous system: evidence for a role in innate immune response through recruitment and activation of natural killer cells. J Virol. 2004;78(2):585-594.

168.McCandless EE, Zhang B, Diamond MS, Klein RS. CXCR4 antagonism increases $T$ cell trafficking in the central nervous system and improves survival from West Nile virus encephalitis. Proc Natl Acad Sci U S A. 2008;105(32):11270-11275. 